\title{
Formação de Trabalhadores e Pesquisa na Construção do Movimento de Ação Solidária de Luta pela Saúde: o caso da Associação Brasileira de Expostos ao Amianto do Rio de Janeiro (ABREA/RJ)
}

Workers Education and Research in the Construction of the Solidarity Action Movement for the Struggle for Health: the case of the Brazilian Association of the Exposed to Asbestos (ABREA/RJ)

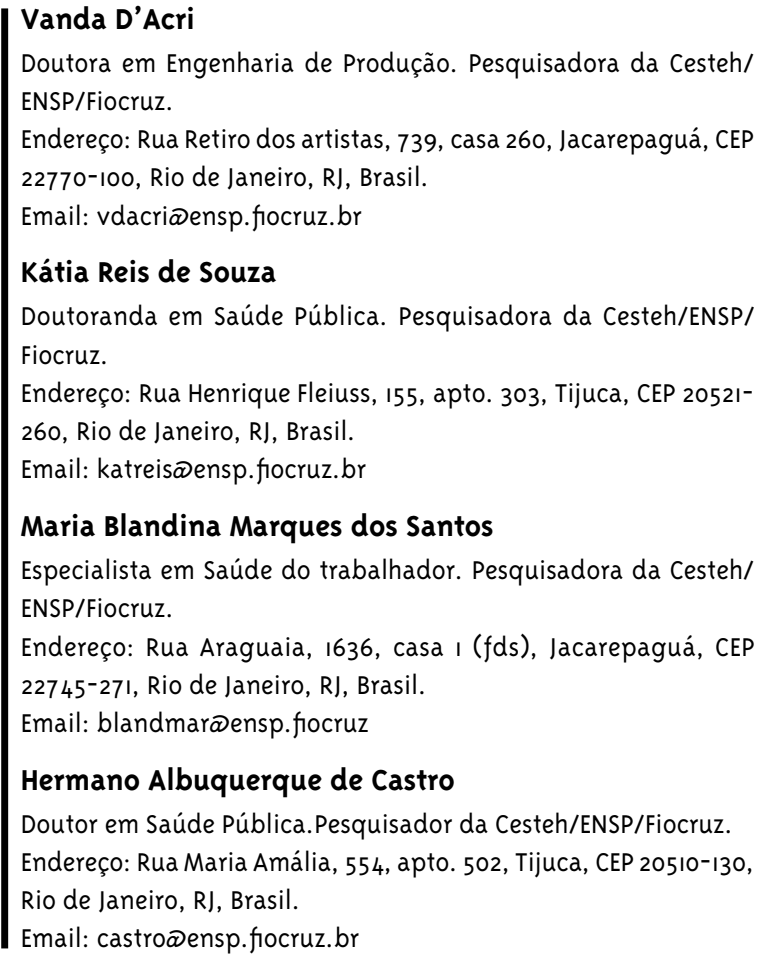

Vanda D'Acri

Doutora em Engenharia de Produção. Pesquisadora da Cesteh/ ENSP/Fiocruz.

Endereço: Rua Retiro dos artistas, 739, casa 260, Jacarepaguá, CEP 22770-100, Rio de Janeiro, RJ, Brasil.

Email: vdacriळensp.fiocruz.br

Kátia Reis de Souza

Doutoranda em Saúde Pública. Pesquisadora da Cesteh/ENSPI Fiocruz.

Endereço: Rua Henrique Fleiuss, 155, apto. 303, Tijuca, CEP 20521260, Rio de Janeiro, RJ, Brasil.

Email: katreisळensp.fiocruz.br

\section{Maria Blandina Marques dos Santos}

Especialista em Saúde do trabalhador. Pesquisadora da Cesteh/ ENSP/Fiocruz.

Endereço: Rua Araguaia, 1636, casa I ( $f d s)$, Jacarepaguá, CEP 22745-271, Rio de Janeiro, RJ, Brasil.

Email: blandmarळensp.fiocruz

\section{Hermano Albuquerque de Castro}

Doutor em Saúde Pública.Pesquisador da Cesteh/ENSP/Fiocruz. Endereço: Rua Maria Amália, 554, apto. 502, Tijuca, CEP 20510-130, Rio de Janeiro, RJ, Brasil.

Email: castroळensp.fiocruz.br

\section{Resumo}

Neste artigo, analisamos o movimento de um grupo de Ação Solidária denominado Associação Brasileira de Expostos ao Amianto do Rio de Janeiro (ABREA/ RJ). Privilegiamos a fala e o ponto de vista dos próprios trabalhadores sobre o movimento, com base no enfoque dos estudos qualitativos e da investigação participativa. Sob a égide do método da educação popular, realizamos reuniões de grupo pautadas na colaboração entre trabalhadores e pesquisadores, o que se mostrou uma estratégia pedagógica facilitadora da reconstrução dos vínculos de solidariedade e da promoção da saúde. Desenvolvemos o argumento de que as práticas de educação em saúde, relativas ao mundo do trabalho, exigem socialização das informações e do conhecimento científico, aliadas a uma ação política integrada que potencialize transformações a favor de uma cidadania plena no trabalho. Outrossim, sustentamos o caráter imprescindível de alguns elementos para a concretização, a contento, de uma práxis educativa em saúde dos trabalhadores, a saber: participação, diálogo, solidariedade e aliança entre trabalhadores e pesquisadores. Por fim, enfatizamos o valor das redes - nas esferas nacional e internacional - de apoio aos trabalhadores no fortalecimento do movimento de banimento do amianto, como também o fato de o próprio trabalho ser um importante ativador da organização de luta pela saúde. 
Palavras-chave: Saúde do trabalhador; Amianto; Luta pela saúde; Grupos de ação solidária; Educação em saúde.

\section{Abstract}

In this article we analyze the movement of a solidarity action group named Brazilian Association of the Exposed to Asbestos of Rio de Janeiro (ABREA/RJ). We focused on the workers' discourse and point of view about this movement, based on the perspective of qualitative studies and participatory investigation. Making use of the methodology of popular education, we have held group meetings based on the collaboration between workers and researchers, which turned out to be a good pedagogical strategy that helped in the reconstruction of solidarity bonds and health promotion. We have developed the argument that the health education practices related to the working world demand socialization of information and of scientific knowledge, together with an integrated political action that enables transformations in favor of a full citizenship in the work context. In order to make this happen we also advocate the indispensable presence of some elements, like participation, dialogue, solidarity and alliance between workers and researchers. Finally, we emphasize the importance of the national and international supporting nets to workers in order to strengthen the movement to proscribe asbestos, as well as the fact that the work itself can be a valuable element that triggers the organization of the struggle for health.

Keywords: Workers' Health; Asbestos; Struggle for Health; Solidarity Action Groups; Health Education.

\section{Introdução}

A partir de 1996, alguns estudos (D’Acri, 2002; Castro e Gomes, 1998; Castro e col., 1999; Castro, 200o) desenvolvidos no Centro de Estudos da Saúde do Trabalhador da Escola Nacional de Saúde Pública da Fundação Oswaldo Cruz (Cesteh/ENSP/Fiocruz), resultantes de trabalho interdisciplinar, tornaram visíveis, em termos epidemiológicos, as doenças causadas pelo amianto aos trabalhadores, no Rio de Janeiro, revelando um grave problema de saúde pública. Complementarmente, fez-se necessário conjugarmos esses trabalhos de cunho teórico com uma intervenção social, uma vez que muitos trabalhadores foram dispensados de suas atividades - adoecidos e sem informações - devido à exposição ao amianto em seus locais de trabalho.

Este artigo é um resultado parcial do projeto de pesquisa intitulado: "Análise das condições de saúde e trabalho dos trabalhadores de uma indústria têxtil de amianto e de cimento amianto e atuação junto ao Sistema Único de saúde para atendimento aos trabalhadores expostos ao amianto no município do Rio de Janeiro"'. Desenvolvemos uma proposta de método educativo pautada nos elementos da pedagogia popular (Freire, 1977, 1978, 1983, 1988, 1997) e na investigação participativa (Brandão, 1986, 1987, 2006), para tornar convergente a produção de conhecimento e o movimento social. Partimos do pressuposto basilar de que a pesquisa e o conhecimento, obtidos através de procedimentos científicos, podem contribuir para uma ação social transformadora, a favor dos trabalhadores. Outra premissa sobre a qual nos ancoramos consiste na ideia de que o trabalho com grupos de discussão é um elemento facilitador, em que são dadas as condições coletivas para se operar a ação educativa, valorizandose a experiência e a cultura dos sujeitos envolvidos (Souza, 2000). Acreditamos que, através das reuniões com grupos de trabalhadores, é possível ativar laços de solidariedade existente entre os trabalhadores e organizar um movimento social e político para o banimento do amianto. Segundo Santos (200o), é possível conhecer criando solidariedade. A solidariedade como forma de conhecimento é o reconhecimento do outro como igual, sempre que a diferença lhe acarrete infe-

1 D'ACRI, V. et al. Análise das condições de saúde e trabalho dos trabalhadores de uma indústria têxtil de amianto e de cimento amianto e atuação junto ao Sistema Único de saúde para atendimento aos trabalhadores expostos ao amianto no município do Rio de Janeiro. Rio de Janeiro: Faperj, 2005. Projeto de pesquisa. Mimeo 
rioridade, e, como diferente, sempre que a igualdade lhe coloque em risco a identidade.

Destaca-se, então, nessa experiência, a importância do papel desempenhado pelas alianças que são criadas para a aproximação de trabalhadores e pesquisadores, justamente por possibilitarem a aquisição de relativa força para o enfrentamento dos antagonismos gerados no âmbito das relações de trabalho capitalista. Nesse contexto, destaca-se a tradição de formação sindical articulada à prática de pesquisa (Oddone e col., 1986), na qual se investiga especialmente a temática referente à saúde no trabalho, com ênfase na aproximação de intelectuais e trabalhadores, o que contribui tanto para a renovação das formas de planejamento da ação operária quanto para o alargamento das fronteiras acadêmicas. Entretanto, a despeito das contribuições inestimáveis de Oddone e colaboradores (1986) para a compreensão do movimento de trabalhadores de luta pela saúde hoje, é indispensável lembrar que a crise política e ideológica pela qual passamos vincula-se à crise social, pois vivemos a era da falta de perspectivas no mundo do trabalho - precarização e desemprego.

\section{O Amianto e a Saúde dos Trabalhadores}

Amianto ou asbesto é uma fibra composta de diversos minerais, como silicatos de magnésio, ferro, cálcio e sódio. Classifica-se em dois grupos: as serpentinas e os anfibólios. Os anfibólios compreendem uma grande variedade de tipos de fibras: a amosita (amianto marrom), a crocidolita (amianto azul), a antofilita, a actnolita e a tremolita. Todo e qualquer tipo de amianto é capaz de causar câncer de pulmão, mesotelioma de pleura, pericárdio ou peritoneo. Pode causar também fibrose pulmonar, conhecida como asbestose, bem como alterações funcionais respiratórias (Castro e Lemle, 1995; Mendes, 2001). Existem ainda outros tipos de câncer relacionado ao asbesto, como o câncer de laringe, o de orofaringe, o de estômago, o de colo retal e o de rim, assim como o câncer na bolsa escrotal e o de ovário (Mendes, 200o).

Estudos na área da epidemiologia revelaram a morbidade e a mortalidade causadas pelo amianto e geraram reações em diversos países, levando à adoção de medidas proibitivas do amianto de tipo anfibólio, considerado um dos mais patogênicos.
Diferentes países têm apresentado projeções de aumento da mortalidade decorrente das doenças relacionadas pelo amianto. Estimativas revelam que milhões de trabalhadores em todo o mundo terão doença causada pelo amianto nas próximas décadas. A previsão da Organização Pan-americana de Saúde, por exemplo, para os Estados Unidos, é a de que, até 2010, 1,6 milhão do total de 4 milhões de trabalhadores expostos à concentração elevada de asbesto morrerão de câncer ocupacional, não estando aí incluídas as pessoas expostas indiretamente (Castro, 200o).

0 valor comercial do amianto está relacionado às suas propriedades físicas: é isolante de calor, tem alta resistência mecânica e baixa condutibilidade elétrica, alta resistência a substâncias químicas agressivas, capacidade de filtrar microorganismos e outras substâncias nocivas, alta durabilidade e baixo custo para sua extração, pois são encontrados em rochas a céu aberto (Castro e Gomes, 1998).

Essas características tornam o amianto um produto muito utilizado industrial e comercialmente. No Brasil, ele tem sido empregado em muitos produtos, principalmente na indústria de fibrocimento, como: caixas d'água, telhas, tubos de água e vasos; na indústria têxtil, como: tecidos em geral, para confecção de luvas industriais, roupas para bombeiros e gaxetas; na produção de papéis, tais como papéis isolantes, papelão hidráulico, papelão industrial, filtros; na indústria automobilística: pastilhas e lonas de freios para automóveis, materiais de fricção, sapatas de trens, juntas de vedação; na produção de pisos vinílicos e outros produtos (Giannasi e col., 1999) (Castro, e col., 2001).

Devido às restrições, em todo o mundo, do uso do amianto e ao comprovado efeito de sua nocividade à saúde humana, buscam-se produtos alternativos para substituí-lo, como é o caso das fibras artificiais minerais, classificadas como não cancerígenas e, portanto, menos perigosas. É importante ressaltar que o Relatório da Comunidade Europeia (1999) estabeleceu o banimento progressivo do amianto em todas as suas formas até 2005. O efetivo cumprimento dessa recomendação exige um movimento com ampla adesão social, contrapondo-se a uma lógica de mercado que permite o adoecimento e a morte de trabalhadores e cidadãos. Lembremos que a proibição do amianto já aconteceu em 45 países, nos quais seus respectivos movimentos sociais devem permanecer na luta, tanto em esfera local, pelos reparos dos danos causados aos 
trabalhadores e ao ambiente, quanto articulados à rede internacional, pelo banimento em todo o mundo.

\section{Os Grupos de Ação Solidária de Trabalhadores e a Luta pela Saúde}

Os movimentos de ação solidária de vítimas no trabalho traduzem-se como organizações que canalizam a participação social e política de trabalhadores que foram dispensados ou não conseguem mais voltar ao trabalho, devido a problemas de saúde adquiridos por consequência da atividade de trabalho que desenvolviam. Apresentam características ou tendências que estão na origem do sindicalismo de quase todos os países ocidentais, como a solidariedade de classe e a luta contra os efeitos do modo de produção capitalista. 0 processo de construção dos laços de solidariedade é fundamental para a formação e a organização mais abrangente da classe trabalhadora, cujos trabalhos com grupos passam a ser um espaço privilegiado de ação. Certamente, esse tipo de movimento, que integra trabalhadores e especialistas, amplia a autoconfiança dos trabalhadores e a sua consciência de classe.

Segundo Hoefel e colaboradores (2004), os Grupos de Ação Solidária têm como objetivo desenvolver a reflexividade e o necessário engajamento nas ações do mundo real. Sua finalidade consiste em abrir um espaço social para a reconstrução da cidadania, para a ressignificação do cotidiano, para o fortalecimento do sujeito e o desenvolvimento de sua autodeterminação. A proposta dos Grupos de Ação Solidária compartilha da concepção de ser humano não como algo pronto, mas como sujeito de relações em contínua construção.

Bobbio e colaboradores (2004) afirma que o Movimento Operário procura sempre adequar aos tempos e lugares as múltiplas manifestações organizativas, preocupando-se em analisar de modo novo e original a sociedade dentro da qual se encontra, inovando as práticas de combatividade. Ressalta ainda, como parte da singularidade do sindicalismo na história ocidental moderna a contínua luta dos trabalhadores pelos seus direitos nos ambientes de trabalho.

Entendemos que a cultura política do ocidente capitalista exclui grande parte dos cidadãos de participarem do poder e do lugar público. No que se refere ao mundo do trabalho, esse fato assume proporções ainda maiores, pois, em geral, os trabalhadores es- tão apartados da prática de participação e decisão. É importante que o trabalhador possa fazer uso da palavra e da crítica, tendo de fato voz e vez. 0 silêncio pode levar o trabalhador ao isolamento e sofrimento. Para Freire, o diálogo é um elemento fundamental da relação pedagógica: com ele, a educação realiza-se em um processo de formação mútua. Isso significa que quem educa está aprendendo também. É uma relação horizontal, e não vertical, entre as pessoas. Como ele afirma: "ninguém educa ninguém. Ninguém se educa sozinho. Os homens se educam juntos, na transformação do mundo" (Freire, 1983).

A maioria dos participantes do movimento das ABREAs no Brasil sofre de doenças graves e irreversíveis (asbestose, câncer de laringe, placas pleurais, entre outras) e já estava praticamente sem esperança de vida, pois foram dispensados do emprego sem direitos ou qualquer tipo de reconhecimento. Movidos pela coletivização da ideia do direito à vida, transformam-se em sujeitos ativos, tanto na busca por reparos sociais quanto na formação de outros trabalhadores que se encontram doentes e isolados. 0 movimento de ação solidária restitui um sentido à vida desses trabalhadores que passam a se sentir incluídos.

\section{Formação de Trabalhadores no Movimento de Luta pela Saúde}

A tese principal sobre a qual nos apoiamos, neste artigo, é a de que a organização e os movimentos relacionados aos trabalhadores são práxis formativa, ou seja, o próprio movimento é ativador do processo formativo dos trabalhadores. Sendo assim, o que almejamos, lançando mão das falas dos próprios trabalhadores, é destacar elementos que confluem para a sua práxis formativa.

Consideramos fundamental o pressuposto da teoria marxista de que o modo de produção da vida material determina a vida social, política e intelectual. Nessa perspectiva, sustentamos o argumento de que a formação de trabalhadores é inseparável de toda a vida social do sujeito, sobretudo a sua própria história no trabalho. Sendo assim, os trabalhadores são intérpretes e autores da contestação e da ruptura por diferentes caminhos, contra as formas de trabalho que matam e adoecem.

Eis aqui a nossa principal acepção de formação: com base no caso da ABREA/RJ, postulamos uma 
prática de educação humanizadora que se contrapõe à exclusão e que se consolida como modo de produção da formação humana. Com isso, estamos defendendo a ideia de cidadania política a partir do trabalho. $\mathrm{Na}$ verdade, trata-se de uma cidadania ampliada, tendo como base a afirmação de que a formação de trabalhadores implica no reconhecimento do domínio de conteúdo do trabalho por parte de cada trabalhador, aliada à consciência do valor do seu saber. Além disso, advogamos a tese de que a debilidade do movimento de trabalhadores, no enfrentamento das antigas e novas formas do conflito capital/trabalho, torna indispensável a participação dos próprios trabalhadores como sujeitos ativos, individual e coletivo, para a construção de novas relações. Portanto, verifica-se que esse é um desafio comprometido com uma forma de observar, explicar e intervir no mundo, transformando-o.

Segundo Coutinho (2002), o desafio é reconstruir um sujeito coletivo a partir de uma enorme multiplicidade de formas de trabalho. Para tanto, as formas de organização dos trabalhadores precisam ser repensadas. O problema é como construir uma hegemonia no pluralismo. Para Coutinho, não se trata mais de construir um sujeito coletivo revolucionário, mas, sim, de construir uma intersubjetividade revolucionária, ou seja, um conjunto de sujeitos plurais e diferentes, mas que convergem e se unificam na luta para uma contínua renovação do movimento organizado de trabalhadores. O movimento de ação solidária de trabalhadores de luta pela saúde é, certamente, um desses caminhos.

Nas palavras de Frigotto (1996, p. 192), "a direção das propostas e práticas educativas devem germinar no interior dos movimentos e organizações da classe trabalhadora e de suas lutas concretas". De acordo com esse autor, a formação em uma perspectiva democrática se gesta no embate contra-hegemônico, de dentro das relações sociais, no interior dos movimentos da classe trabalhadora, o que favorece a emancipação política dos sujeitos participantes e suas lutas.

\section{As ABREAs e alguns Marcos no Movimento pelo Banimento do Amianto}

Existem atualmente, no Brasil, seis Associações de Expostos ao Amianto (ABREAs), que estão organizadas e legalmente formalizadas. Três estão localizadas no
Estado de São Paulo (com grupos locais em Osasco, São Caetano e Paraíba do Sul), uma, na cidade do Rio de Janeiro e duas, na Bahia (Simões Filho e Poções). Estão em processo de organização as do Estado de Minas Gerais, do Paraná e de Goiás. Esses movimentos têm recebido as mais variadas adaptações e soluções na estruturação de sua ação em rede. Entretanto, destacamos o papel precursor da ABREA de Osasco.

Apresentam como características gerais:

- A capacidade de articulação e aproximação de trabalhadores, que estão doentes e isolados, para a luta pelo reparo dos danos sociais, morais, trabalhistas e políticos;

- A participação do movimento nacional e internacional de banimento do amianto;

- A promoção de uma rede de apoio aos trabalhadores, vítimas da exposição ao amianto, principalmente através do diálogo entre trabalhadores, pesquisadores e técnicos do campo da saúde e do trabalho para, entre outras ações, lutar contra todas as formas de trabalho relacionadas ao amianto que geram adoecimento e morte;

- A divulgação dos danos gerados pela exposição ao amianto, tendo os trabalhadores como protagonistas do movimento e multiplicadores das informações.

Quanto ao movimento social organizado pelo banimento do amianto, uma referência norteadora ainda é o Seminário Internacional de Milão - marco mundial -, realizado em abril de 1993, em que o amianto foi considerado perigoso sob qualquer forma, e independentemente da quantidade, no processo produtivo, no processo extrativo, e também no seu transporte, transformação, utilização e eliminação.

O documento intitulado “Apelo de Milão," relatório final do Seminário Internacional Bastamianto, produzido na Itália, em 1993, recomenda proibir todas as formas de uso de amianto e sua substituição por outras matérias-primas menos nocivas à saúde. Essa recomendação não é apenas circunscrita à Europa, mas a todo o Planeta.

No período de 28 a 30 de março de 1994, realizou-se em São Paulo o Seminário Internacional, promovido pela Fundacentro (Fundação Jorge Duprat Figueiredo de Segurança e Medicina do Trabalho), pela CUT (Central Única dos Trabalhadores) e pela Força Sindical. Esse seminário apoiou as diretrizes do Documento de Milão, adotando a expressão política "Um Mundo sem Amian- 
to", e constituiu a Rede Virtual Cidadã para o Banimento do Amianto - Ban Asbestos (Giannasi, 2002).

A Rede Mundial Ban Asbestos (Ban-Asbesto network) é composta de organizações não-governamentais e movimentos sociais das Américas e Europa, como a Federação Ban Asbestos (Ban Asbestos European Federation-Baef). Segundo Giannasi (2002), apesar das barreiras geográficas, linguísticas e políticas, essa rede tem como objetivos: mapear as multinacionais do amianto, que sustentam a tese do seu uso controlado e seguro, e atuar propositivamente quanto aos governos que ainda não baniram o amianto sob todas as suas formas, para que o façam imediatamente e que promovam o uso de produtos substitutivos menos nocivos, com a garantia dos empregos e a promoção de ações sociais e de direito a suas vítimas.

No Seminário Nacional, organizado pelo Centro de Estudos da Saúde do Trabalhador e Ecologia Humana, Cesteh/ENSP/Fiocruz, realizado nos dias 15 e 16 de maio de 1997, no Estado do Rio de Janeiro, discutiu-se, pela primeira vez, a situação de saúde dos trabalhadores ocupacionalmente expostos ao amianto no Estado, o que trouxe visibilidade aos agravos provocados pela substância no processo de trabalho. Participaram desse seminário, além de instituições publicas - da área de ensino, pesquisa e serviços da rede pública de saúde -, a ABREA de São Paulo e centrais sindicais. Foram produtos desse seminário o documento denominado a "Carta do Rio" e um elenco de propostas, como a criação de um Fórum Estadual Permanente do Amianto. Deliberou-se pela construção coletiva de um sistema de referência e contrarreferência para assistência à saúde do trabalhador, vigilância e educação ambiental. Em 1998, no período de 2 a 4 de setembro, em convênio entre a ENSP/Fiocruz e a Universidade de Padova, na Itália, realizou-se o Seminário Internacional, também organizado pelo Cesteh, cujo tema central foi "As fibras alternativas e as novas tecnologias de substituição ao amianto". Os temas debatidos nos seminários e fóruns pautavam a luta das ABREAs.

Destacamos na trajetória desse movimento o protagonismo dos trabalhadores no que se refere à sua organização, mobilização ativa e busca pela participação de outros trabalhadores, inclusive aqueles o estão trabalhando expostos ao amianto em diferentes locais de trabalho. A história desse movimento no Rio de Janeiro culminou com a fundação da ABREA/RJ, em 11 de maio de 2001.
A relação entre produção/consumo do amianto e a saúde dos trabalhadores remete a uma análise de luta de classes, em que há interesses distintos. 0 movimento dos trabalhadores e suas organizações enfrentam os interesses do empresariado, que, em esfera nacional, defende a permanência do amianto nos processos produtivos, alegando que seu uso controlado não oferece agravos nem à saúde nem ao meio ambiente. Diante disso, temos um quadro de relativa fragilidade do movimento, que necessita de alianças de diversos setores da sociedade para apoio de suas conquistas. Um exemplo é o que acontece no âmbito da aprovação das leis do amianto. Houve algumas leis estaduais e municipais aprovadas para o banimento do amianto ou para sua substituição progressiva, mas poucas continuam em vigor. A do Rio de Janeiro, Lei ${ }^{\circ} 3579$, de 7 de julho de 2001, ordena que, a partir de janeiro de 2005, não se utilize mais amianto no Estado. Contudo, estamos em 2008 e ele continua sendo utilizado sem qualquer regulação pública jurídica satisfatória. Além disso, leis aprovadas em outros Estados - como São Paulo - foram questionadas através de "Ações Diretas de Inconstitucionalidade" (ADI), nas quais os autores, estranhamente dizendo-se representar os trabalhadores, alegam a existência de uma lei Federal anterior sobre a matéria, que garante o uso seguro do amianto, e que os Estados estariam invadindo a competência da União ao legislar matéria já publicada. Essa situação se tornou para o movimento social um desafio a ser enfrentado. Finalmente, em decisão histórica, que representa um divisor de águas na luta pelo banimento do amianto em nosso país, uma decisão de 4 de junho de 2008 , pôs por terra uma tradição reiterada pelo Supremo Tribunal federal (STF) em impedir que Estados legislassem sobre matérias que a Constituição Federal fez avançar em 1988, como sendo de competência concorrente. Assim a lei paulista $\left(\mathrm{n}^{0} 12.684 / 2007\right)$ que estava impedida de entrar em vigor por força de liminar foi enfim considerada constitucional.

\section{Procedimentos Metodológicos}

Com base no enfoque dos estudos qualitativos em saúde (Minayo, 1994; Minayo e col., 2005; Lefèvre e Lefèvre, 2005) e da investigação participativa (Brandão, 1987, 2006), realizamos reuniões com os trabalhadores entendendo que os grupos de discussão são fontes 
privilegiadas de informação sobre a relação saúdetrabalho. Nossos encontros abertos ocorreram de 2005 a 2007, com ampla divulgação e mobilização entre os trabalhadores que participam do movimento da ABREA/RJ, e foram realizados mensalmente na sede da sua Associação. Todo o material levantado a partir do discurso dos trabalhadores serviu como matéria-prima para reflexão e ação do movimento. 0 grupo favoreceu o estabelecimento de inter-relações e o qualificativo "solidariedade", que o nomeia, remete a essa dependência e responsabilidade mútuas. Assim, os Grupos de Ação Solidária têm o objetivo de se constituir como um lugar para compartilhar experiências e propor ações de engajamento social. Não se restringem à busca de soluções de problemas individuais, pois se privilegia a proposição de ações coletivas com potencial de transformação social (Hoefel e col., 2004). Os grupos aparecem como possibilidade de criar mediações e servem como estratégia pedagógica para o processo de produção de conhecimento, contribuindo com uma forma de produção coletiva do saber e ampliando o projeto de ação, renovando as práticas de investigação e, em particular, as investigações de caráter participativo (Brandão, 1986, 1987, 2006).

Destacamos o caráter ativo do conhecimento como atividade prática e concreta. Com Minayo (1994) e Thiollent (1986), podemos concluir que a pesquisa participante é uma modalidade de pesquisa-ação, pois é um tipo de investigação social com base empírica, concebida e realizada em estreita associação com ação ou resolução de um problema coletivo no qual os pesquisadores e os participantes representativos da situação ou do problema estão envolvidos de modo cooperativo ou participativo.

Trata-se, neste estudo, de uma ciência comprometida, moldada por interesses e visões de mundo historicamente construídos. As visões de mundo dos pesquisadores e dos trabalhadores estão implicadas em todo processo de pesquisa na construção do movimento de ação solidária de luta pela saúde.

\section{As Reuniões e os Grupos de Discussão da ABREA/RJ}

Durante as reuniões com grupos de trabalhadores participantes da ABREA do Rio de Janeiro, selecionamos e analisamos as falas que qualificam os elementos que confluem, entre outros, a uma práxis formativa de trabalhadores, sendo os principais:

\section{O Movimento de Luta pela Saúde dos Trabalhado- res para Solução de Problemas}

Olha, quando iniciei, sinceramente, não sabia que daqui a 20 anos esse veneno apareceria com suas doenças, como: câncer, endurecimento dos pulmões, que impedem a respiração, dor nas costas, e outras doenças, e, por fim, a morte... Nós queremos a abertura da ABREA para resolver o problema da nossa saúde e também das mortes. Esse veneno amianto causa muitas doenças. (Trabalhadora Francisca)

Com essa reunião do amianto, foi e vai continuar sendo agradável o encontro de nossos colegas, que estão juntos nessa luta sofrida e sofrem pelos danos do amianto. Sem ter saúde, conversando com os outros que também sofrem, discutindo a nossa ideia, discutindo para o nosso bem... mais do que nunca nós queremos uma solução. (Trabalhador Pedro)

A crítica coletiva possibilita compreender a realidade e, ao mesmo tempo, funciona como incentivo para a busca de soluções, principalmente por meio da organização política dos trabalhadores. Os grupos de discussão são instrumentos de ações pedagógicas formativas entre os próprios sujeitos participantes - através da troca de experiência e do uso da palavra - quanto são estímulos à capacidade de ação para busca de soluções dos problemas relativos aos direitos. Neles, problematiza-se o quadro de degradação das condições de vida pelo trabalho e, muitas vezes, relacionam a não solução de problemas à ausência do Estado na formulação e efetivação de políticas e estratégias de proteção social.

\section{A Reconstrução dos Vínculos de Solidariedade nos Encontros e Grupos de trabalhadores}

Nossa luta trouxe não só os antigos colegas de trabalho, também outros trabalhadores que foram vítimas inocentes do amianto. $O$ amianto mata mesmo! Mata a esperança de voltarmos a trabalhar; o trabalho é dignidade [...]. Fomos dispensados após anos de dedicação ao trabalho, sem nenhum reconhecimento e nenhuma informação dos problemas que o amianto causou à nossa saúde [...]. Hoje, sabemos que o amianto causa câncer e várias doenças no pulmão [...]. Sentimos também 
na nossa pele outros problemas como micoses. (Trabalhadora Dora)

Eu sentia-me morta, enterrada; depois que comecei no movimento, no Cesteh, voltei a viver, é como se tivessem me desenterrado [...] Nosso movimento é pelo resgate de nossa dignidade. $O$ nosso movimento é a luta pela vida [...]. Estamos estudando e nos informando sobre o amianto: participamos de seminários, congressos e debates. (Trabalhadora Francisca)

A situação de saúde pela qual esses trabalhadores estão passando impede que eles retornem ao mercado formal de trabalho, o que traz, em contrapartida, um sentido de valorização ao movimento, no que se refere à possibilidade de compartilhar sentimentos e perdas, e de conquista/reconquista de um novo sentido de luta pela vida. É comum, nas reuniões de grupo, a expressão de sentimentos como a tristeza pela perda de companheiros que morrem devido aos problemas de saúde, acompanhada do imediato apoio, recíproco, manifestado muitas vezes pelo sentimento de alegria por estarem juntos e poderem superar a sensação de impotência. Além disso, a ação solidária, praticada nos grupos de trabalhadores doentes e com diagnóstico de doenças crônicas irreversíveis, possui uma dimensão simbólica importante para a promoção da saúde. A vida está intimamente relacionada à morte nas falas e nos relatos. $\mathrm{O}$ encontro torna-se uma arte que produz novas subjetividades, contornando o medo e a falta de informação.

\section{o Grupo de Discussão como Ferramenta de Inter- venção e Promoção do Diálogo sobre a Saúde}

[...] falar sobre o nosso encontro com os trabalhadores é uma coisa muito importante. Na troca de ideias a gente vai reagindo [...] vendo o que é preciso e necessário; por exemplo: esse veneno que perturba há anos, o amianto e algumas outras químicas que andam por aí. Para nós já somos vítimas de uma delas, que ainda está sendo utilizada. Tem que melhorar esta política de um jeito ou de outro. Assim não pode continuar... E agora uma pergunta: por que o empregado pode ser explorado? (Trabalhadora Joana)

Para Freire (1986), chegamos a uma educação dialogal e ativa, voltada para a responsabilidade social, ao lançar mão da transitividade crítica, que se caracteriza pela substituição de explicações mágicas pela profundidade na interpretação dos problemas. Do ponto de vista do trabalho pedagógico nos grupos, a crítica é a viabilidade do projeto democrático de diálogo sobre a saúde. É a possibilidade de a classe trabalhadora apreender o método dialético de interpretação do real.

A democratização do saber passa pelo fato de o trabalhador poder conhecer, de forma mais organizada, os reais efeitos do trabalho sobre a sua saúde, a partir de discussões - acerca do que ele conhece melhor a respeito da sua experiência de trabalho - travadas com os pesquisadores. Esse se constitui um dos aspectos principais do processo educativo de democratização do saber dos grupos de caráter solidário em saúde. Aqui, outra importante referência metodológica é o conceito de "Não delegar", desenvolvido por Ivar Oddone e colaboradores (1986), cuja definição consiste em "não confiar ao patrão e aos seus representantes o controle dos efeitos nocivos do trabalho" (Oddone e col., 1986, p. 54).

A socialização do conhecimento sobre a relação saúde-trabalho representa a modificação das condições históricas de apropriação do conhecimento sobre a relação saúde-trabalho, que, em geral, restringi-se ao domínio de especialistas; os grupos de discussão procuram minimizar a situação de poder assimétrica em que se encontram os trabalhadores, criada pela divisão social do trabalho tradicional na sociedade capitalista.

Para que o ambiente de trabalho fique livre da nocividade que sempre o acompanhou é necessário que as descobertas científicas neste campo sejam socializadas, isto é, trazidas ao conhecimento dos trabalhadores de uma forma eficaz. É necessário que a classe operária se aproprie delas e se posicione como protagonista na luta contra as doenças, as incapacidades e as mortes no trabalho. (Oddone e col., 1986, p. 17.)

\section{Fortalecimento da Rede de Apoio aos Trabalha- dores com a Adesão de Outros Segmentos da Sociedade}

Nós trabalhadores temos uma grande luta pela frente, mas precisamos de muito apoio. Queremos melhorar cada vez mais, é necessário para nossa vida ficar melhor. (Trabalhadora Margarida) 
Berlinguer (1996) sugere que pensemos sobre a função de uma "cultura da saúde", utilizando mais amplamente os recursos da solidariedade espontânea e organizada, que, além reparar os danos, trabalhe para ampliar o impacto positivo que toda atividade humana pode desenvolver em prol da saúde com base no trabalho e na produção. A construção das redes de apoio a trabalhadores, para o fortalecimento da luta pela saúde, expressa-se como um sintoma de vitalidade, que é ação sobre o mundo real.

\section{Considerações Finais}

Sustentamos que os processos participativos de diálogo sobre a saúde contribuem para a humanização de seus sujeitos - que se reconhecem cada vez mais como sujeitos de direito e da informação -, sendo a experiência no trabalho o ponto de referência para a formação sobre a produção de uma subjetividade ética de coresponsabilidade pela saúde no trabalho. A ABREA é, portanto, um passo afirmativo dos trabalhadores no Estado do Rio de Janeiro em direção da construção de relações sociais solidárias, a partir de um modo de vida que, por intermédio da ação coletiva, produz saúde.

Segundo Bobbio e colaboradores (2004), os movimentos operários, partidos socialistas de classe e organizações de trabalhadores constituem um todo unitário, não estático no tempo, mas atuante de modos diferentes nas diversas situações históricas. Desse modo, esses movimentos atuais de luta pela saúde devem se articular diretamente aos movimentos sindicais - e a outros existentes - e às centrais de trabalhadores, o que contribuirá para dar vida nova à agenda de lutas e para o fortalecimento e a capacidade dos movimentos organizados do trabalho.

\section{Referências}

BERLINGUER, G. Ética da saúde. São Paulo: Hucitec, 1996.

BOBBIO, N.; MATTEUCCI, N.; PASQUINO, G.

Dicionário de política. Brasília, DF: Ed. Universidade de Brasília, 2004.

BRANDÃO, C. R. Pesquisa participante. São Paulo: Brasiliense, 1986.
BRANDÃO, C. R. Repensando a pesquisa participante. 3. ed. São Paulo: Brasiliense, 1987.

BRANDÃO, C. R. Pesquisa participante: o saber da partilha. São Paulo: Idéias \& Letras, 2006.

CASTRO, H. A. Busca de marcadores inflamatórios $I L-1 B, 1 L-6$ e TNFa em trabalhadores expostos a poeiras minerais. 20oo. Tese - Escola Nacional de Saúde Pública, Fiocruz, Rio de Janeiro, 2000.

CASTRO, H. A. et al. Estudo das condições de saúde, trabalho e vida dos trabalhadores de uma indústria têxtil de amianto no Rio de Janeiro. Rio de Janeiro: Fiocruz, ENSP, 1999.

CASTRO, H. A. et al. Implantação de um Sistema Integrado de Vigilância em Saúde do Trabalhador para áreas que utilizam o amianto no Brasil. Rio de Janeiro: ENSP, CESTEH, 2001.

CASTRO, H.; LEMLE, A. Doenças do aparelho respiratório relacionadas à exposição ao asbesto. In: VIEIRA, S. I. (Org.). Medicina básica do trabalho. Curitiba: Gênesis, 1995. v. III.

CASTRO, H.; GOMES, V. R. Doenças do aparelho respiratório relacionadas à exposição ao asbesto. Revista Pulmão, Rio de Janeiro, v. 6, n. 3, p. 162-170, jan./mar. 1997.

COUTINHO, C. N. A democracia na batalha das idéias e nas lutas políticas do Brasil de hoje. In: FÁVERO, O.; SAMERARO, G. (Org.). Democracia e construção do público no pensamento educacional brasileiro. Petrópolis: Vozes, 2002. p. 11-40.

D'ACRI, V. O significado do trabalho, o estudo das condições de trabalho e saúde dos trabalhadores de uma indústria têxtil de amianto no Rio de Janeiro. 2002. Tese - COPPE, UFRJ, Rio de Janeiro, 2002.

FREIRE, P. Extensão ou comunicação? Rio de Janeiro: Paz e Terra, 1977.

FREIRE, P. Cartas à Guiné Bissau: registros de uma experiência em processo. 4. ed. Rio de Janeiro: Paz e Terra, 1978.

FREIRE, P. Educação como prática de liberdade. 14. ed. Rio de Janeiro: Paz e Terra, 1983. 
FREIRE, P. Criando métodos de pesquisa alternativa: aprendendo a fazê-la melhor através da ação. In:

BRANDÃO, C. R. Pesquisa participante. 6. ed. São Paulo: Brasiliense, 1986. p. 34 -41.

FREIRE, P. Pedagogia do oprimido. 10. ed. Rio de Janeiro: Paz e Terra, 1988.

FREIRE, P. Pedagogia da autonomia: saberes necessários à prática educativa. São Paulo: Paz e Terra, 1997.

FRIGOTTO, G. Educação e a crise do capitalismo real. 2. ed. São Paulo: Cortez, 1996.

GIANNASI, F. A construção de contrapoderes no Brasil na luta contra o amianto: a globalização por baixo. In: R. Mendes. Patologia do trabalho. 2. ed. atual. e ampl. São Paulo: Atheneu, 2002. 2 v.

GIANNASI, F., SCAVONE, L., MONY, A. T. Doenças laborais provocadas pelo amianto e a construção de uma cidadania de protesto: uma abordagem interdisciplinar em saúde do trabalho, meio ambiente e gênero. Revista CIPA, São Paulo, v. 235, n. 2o, p. 54-57, 1999.

HOEFEL, M. da G. et al. Uma proposta em saúde do trabalhador com portadores de LER/DORT: grupos de ação solidária. Cadernos de Psicologia Social do Trabalho, São Paulo, v. 7, p. 31-39, dez. 2004.

LEFÈVRE, F.; LEFÈVRE, A. M. C. O discurso do sujeito coletivo: um novo enfoque em pesquisa qualitativa (desdobramentos). Caxias do Sul, RS: EDUCS, 2005 .
MENDES, R. Asbesto (amianto) e doença: revisão do conhecimento científico e fundamentação para uma urgente mudança da atual política brasileira sobre a questão. Cadernos de Saúde Pública, Rio de Janeiro, v. 17, n. 1, p. 7-29, 2001.

MENDES, R., Efeitos Sobre a Inalação de Fibra de Amianto sobre a Saúde Humana. Texto apresentado no Congresso Mundial do Asbesto: Passado, Presente e Futuro. São Paulo, set. 20oo. Mimeo.

MINAYO, M. C. S. O desafio do conhecimento: pesquisa qualitativa em saúde. 3. ed. São Paulo: Hucitec; Rio de Janeiro: Abrasco, 1994.

MINAYO, M. C. S; ASSIS, S. G.; SOUZA, E. R. (Org.). Avaliação por triangulação de métodos: abordagem de programas sociais. 2. ed. Rio de Janeiro: Fiocruz, 2005 .

ODDONE, I. et al. Ambiente de trabalho: a luta dos trabalhadores pela saúde. São Paulo: Hucitec, 1986.

SANTOS, B. S. A crítica da razão indolente: contra o desperdício da experiência. São Paulo: Cortez, 2000. SOUZA, K. R. Para uma pedagogia da saúde no trabalho: elementos para um processo educativo em saúde do trabalhador. 20oo. Dissertação (Mestrado em Educação) - Núcleo de Tecnologias Educacionais para a Saúde da UFRJ, Rio de Janeiro, 2000.

THIOLLENT, M. Metodologia da pesquisa-ação. 2. ed. São Paulo: Cortez, 1986. 